\title{
Hematopoietic myelomonocytic cells are the major source of hepatocyte fusion partners
}

\author{
Fernando D. Camargo,, 1,2 Milton Finegold, ${ }^{3}$ and Margaret A. Goodell1,2,4 \\ ${ }^{1}$ Center for Cell and Gene Therapy, ${ }^{2}$ Cell and Molecular Biology Program, ${ }^{3}$ Department of Pathology, and ${ }^{4}$ Department of Pediatrics, \\ Baylor College of Medicine, Houston, Texas, USA.
}

\begin{abstract}
Several recent reports have demonstrated that transplantation of bone marrow cells can result in the generation of functional hepatocytes. Cellular fusion between bone marrow-derived cells and host hepatocytes has been shown to be the mechanism of this phenomenon. However, the exact identity of the bone marrow cells that mediate cellular fusion has remained undetermined. Here we demonstrate that the hematopoietic progeny of a single hematopoietic stem cell (HSC) is sufficient to produce functional hepatic repopulation. Furthermore, transplantation of lymphocyte-deficient bone marrow cells and in vivo fate mapping of the myeloid lineage revealed that HSC-derived hepatocytes are primarily derived from mature myelomonocytic cells. In addition, using a Cre/lox-based strategy, we directly demonstrate that myeloid cells spontaneously fuse with host hepatocytes. Our findings raise the possibility that differentiated myeloid cells may be useful for future therapeutic applications of in vivo cellular fusion.
\end{abstract}

\section{Introduction}

Several recent studies have demonstrated the ability of bone marrow $(\mathrm{BM})$ cells to produce cells of multiple tissues, including skeletal and cardiac muscle (1-3), endothelium $(2,4)$, neurons (5), and epithelial cells of the lung (6), gut $(6,7)$, skin $(6,8)$, and liver (9-11). Collectively, these reports led many investigators to question the view that germ layer and lineage commitment are temporally restricted to embryonic development. These data bear singular importance not only because of their biological interest, but also due to their enormous therapeutic implications. However, the concept of so-called stem cell "plasticity" has been challenged by recent findings. Failure to reproduce initial experiments (12-14), the very low levels of transdifferentiation events in several animal models, and recent findings demonstrating cell fusion as the mechanism of transdifferentiation (15-17) argue against the physiological significance of stem cell plasticity. A further understanding of the cellular mechanisms involved in the regeneration of nonhematopoietic tissues by BM cells is required before we can apply any of these observations in the clinical setting.

In the case of BM transdifferentiation into liver, it was originally demonstrated that cells derived from the BM could generate functional hepatocytes and rescue a liver metabolic disease (10). In the report by Lagasse et al., transplantation of as few as 50 highly purified hematopoietic stem cells (HSCs) was sufficient for the generation of functional hepatic nodules (10). However, formal and direct demonstration that a single cell could serve as a progenitor for both hematopoietic and hepatic lineages was never provided. In addition, recent data have demonstrated that cellular fusion between BM-derived cells and host hepatocytes accounts for the principal mechanism of blood-to-liver regenera-

Nonstandard abbreviations list: bone marrow (BM); 3,5-dietoxycarbonyl-1,4-dihydrocollidine (DDC); fumarylacetoacetate hydrolase (FAH); hematopoietic stem cell (HSC); lysozyme-M (LysM); 2-(2-nitro-4-trifluoromethylbenzol)-1,3-cyclohexanedione (NTBC); phycoerythrin (PE); side population (SP); whole BM (WBM).

Conflict of interest: The authors have declared that no conflict of interest exists.

Citation for this article: J. Clin. Invest. 113:1266-1270 (2004).

doi:10.1172/JCI200421301. tion (15-17). However, the identity of the BM-derived cells that act as hepatocyte fusion partners has remained undetermined.

In the present work, by transplanting single isolated HSCs, we demonstrate, for the first time to our knowledge, that one hematopoietic cell can serve as progenitor for both blood and functional hepatocytes. Furthermore, we establish that BMderived hepatocytes are primarily derived from hematopoietic cells of the myeloid, but not of the lymphoid, lineage. In addition, using a Cre/lox DNA recombination-based strategy, we directly show that mature myeloid cells spontaneously fuse with host hepatocytes. Our findings raise the possibility that localized administration of fusogenic cells such as myeloid cells could be a new strategy for cellular therapy of multiple tissues.

\section{Results}

In order to unambiguously demonstrate that HSCs could give rise to both blood and hepatocytes, we decided to follow the progeny of a single prospectively isolated HSC after transplantation into lethally irradiated host mice. Single side population (SP) $\mathrm{CD}_{4}{ }^{+}$cells from CD45.2 Rosa26 mice were transplanted into irradiated CD 45.1 congenic recipients; hematopoietic and hepatic engraftment was analyzed in these primary hosts. Subsequently, HSC-derived BM cells from the primary hosts were transplanted into mutant secondary recipients for subsequent liver-engraftment analysis.

As previously reported (12), approximately $25 \%$ of primary single-HSC recipients showed long-term and multilineage hematopoietic chimerism. Four mice with higher than $60 \%$ singlecell-derived blood engraftment were selected for liver-engraftment analysis. Two of these mice were treated with the hepatotoxin 3,5-dietoxycarbonyl-1,4-dihydrocollidine (DDC) (18). Fourteen months after transplantation, liver samples were examined by $\mathrm{X}$-gal staining. We detected donor cells displaying a characteristic hepatocyte-like morphology at frequencies of 1 in 300,000 and 1 in 150,000 for the noninjured and DDC-treated mice, respectively (Figure 1A). Donor hepatocyte-like cells were found primarily as isolated cells, and, in a few cases in the DDC-treated group, as clusters of two and, in one case, three cells (data not shown). 
A
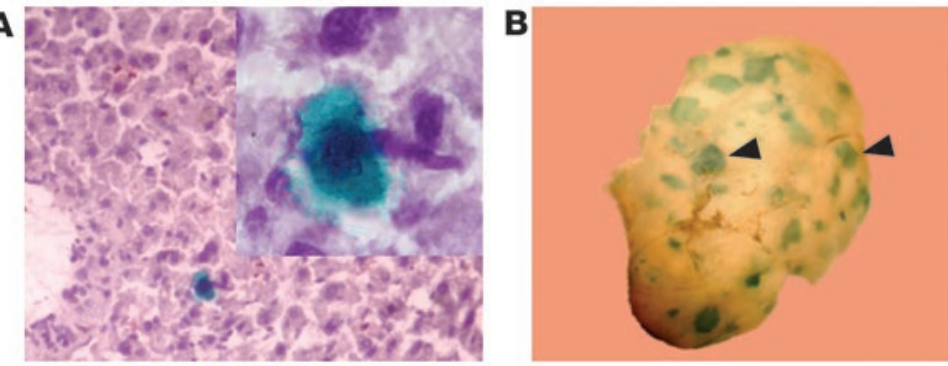

C

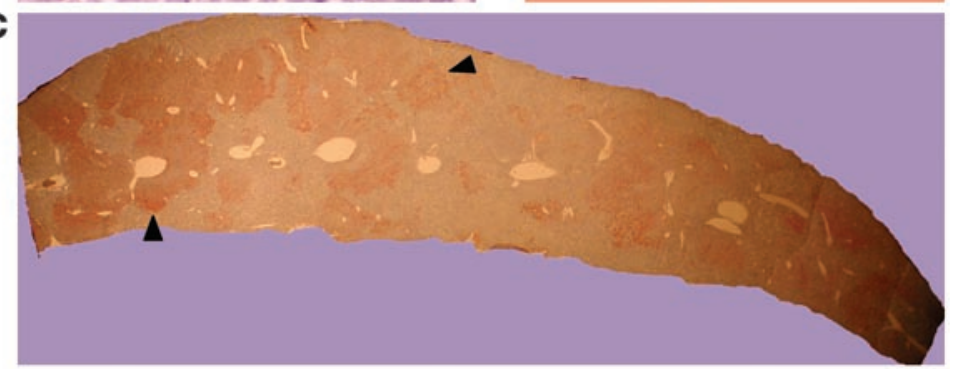

D

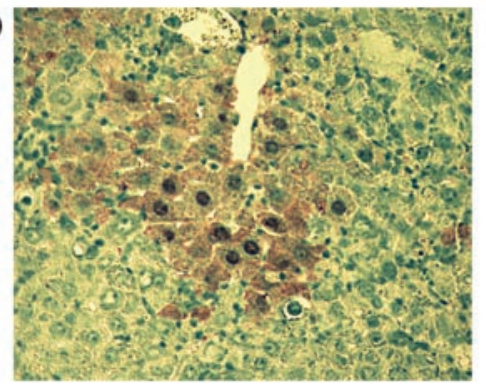

E
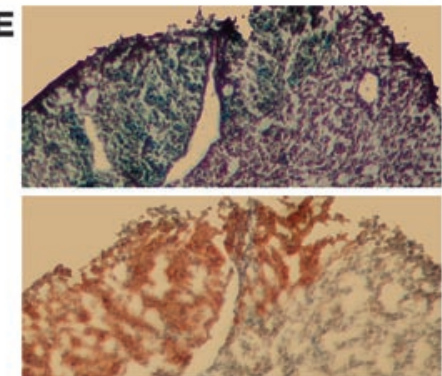

\section{Figure 1}

Hepatic differentiation after transplantation of a single HSC. Fourteen months after transplantation of a single $\beta$-gal ${ }^{+}$ HSC, random liver sections were analyzed by $X$-gal staining. (A) Cells with hepatocyte morphology (large cells with abundant cytoplasm) that clearly expressed $\beta$-gal and were integrated into the liver parenchyma were detected in primary single-cell recipients. The micrographs were taken at $\times 20$ magnification, with the inset at $\times 100$. Clonally derived hematopoietic BM cells were harvested from primary recipients and transplanted into Fah ${ }^{-/-}$mice. (B) Five months after transplantation, whole-mount $\mathrm{X}$-gal staining on liver lobes revealed extensive blue nodular repopulation (arrowheads). (C) FAH immunohistochemistry (dark brown staining) shown on a liver section confirms widespread oligoclonal repopulation throughout the host parenchyma (arrowheads). (D) Increased magnification of a repopulated nodule reveals typical hepatocyte morphology of the brown $\mathrm{FAH}^{+}$cells. (E) Frozen serial sections stained with $\mathrm{X}$-gal and anti-FAH show colocalization of staining, confirming that the $\mathrm{FAH}$ expression is derived from the original Rosa26 (lacZ+) HSC.

cells derived from a single HSC can produce, in addition to hematopoietic cells, fully functional hepatocytes and correct a metabolic disease.

Although these results indicate that cells derived from a single HSC can produce functional hepatocytes, it was unclear whether the HSC itself or its differentiated hematopoietic progeny fused with the host hepatocytes. In order to test whether mature hematopoietic cells of the lymphoid lineage could act as fusogenic partners for hepatocytes, we transplanted $1 \times 10^{6}$ WBM cells from

In order to more rigorously assess the hepatic potential of HSCs, BM cells derived from the single HSC were isolated by flow cytometry on the basis of their expression of the CD45.2 allele and transplanted into lethally irradiated recipients that were deficient in expression of fumarylacetoacetate hydrolase (FAH), an essential liver enzyme (19). Fah ${ }^{-1-}$ mice can be maintained on the drug 2-(2-nitro-4-trifluoromethylbenzol)-1,3-cyclohexanedione (NTBC), and transplantation of whole BM (WBM) cells has previously been shown to rescue this deficiency $(10,20)$. In the absence of NTBC, normal hepatocytes possess a remarkable selective growth advantage and can repopulate a mutant liver. In order to maximize survival of BM-recipient mice, NTBC therapy was intermittently reinstituted and withdrawn. After verification of hematopoietic engraftment, 4-7 months after transplantation, the $\mathrm{Fab}^{-/-}$transplant recipients were sacrificed and their livers analyzed histologically. Whole-mount X-gal staining of liver lobes for $\beta$-gal ${ }^{+}$cells originally derived from the single HSC revealed extensive liver repopulation comprising about $40-60 \%$ of the hepatic parenchyma (Figure 1B). Hepatic engraftment, in agreement with previous reports $(10,20)$, appeared oligoclonal in nature, with approximately $200-400 \beta$-gal ${ }^{+}$nodules of repopulation per mouse liver, similar to the prevalence of repopulation clusters observed after WBM transplantation. Histochemical analysis of livers of transplanted mice revealed extensive areas of cells with hepatocyte morphology expressing both the hepatocyte-specific FAH enzyme and $\beta$-gal (Figure 1, C-E). Furthermore, serum biochemical measurements of liver function were taken. Transplanted mutant mice showed nearly wild-type levels of all functional indicators analyzed (Table 1). These results strongly indicate that mice deficient in both recombinase-activating gene 2 (Rag- 2 ) and the common cytokine receptor $\gamma$ chain $(\gamma \mathrm{c})$ into $\mathrm{Fab}^{-1-}$ hosts. Absence of both Rag- 2 and $\gamma c$ in mice results in the complete absence of circulating B, T, and NK cells, but normal numbers of myeloid and erythroid progeny (21). Four weeks after BM transplantation, NTBC withdrawal was initiated in order to select for $\mathrm{FAH}^{+}$hepatocytes. Transplanted mice were able to survive in the absence of NTBC and were maintained without the drug for more than 5 months. Immunohistochemical staining of liver sections from these mice revealed typical $\mathrm{FAH}^{+}$nodules throughout the liver parenchyma (data not shown). The kinetics of repopulation and the number of $\mathrm{FAH}^{+}$nodules per section (Table 2) in these mice were no different from those in mice transplanted with normal BM. These data suggest that cells of the lymphocyte lineage are not required as hepatocyte fusion partners.

Next we wanted to evaluate the hepatic contribution of mature hematopoietic cells of the myeloid lineage. In order to trace myeloid cells in vivo, we used Cre/lox recombination, wherein Cre recombinase, specifically expressed in myeloid cells under the endogenous regulatory sequences of the lysozyme-M (LysM) gene (22), irreversibly unblocks expression of a $\beta$-gal reporter (R26R) (23), thus marking all myeloid cells and their downstream progeny. The LysM locus in mice is exclusively active in hematopoietic cells of the myelomonocytic lineage, being expressed moderately in committed myeloid progenitors and expressed highly in mature macrophages and neutrophils. We transplanted $1 \times 10^{6} \mathrm{BM}$ cells from mice that were transgenic for both the LysM-Cre gene and the R26R gene (LysM-Cre/R26R), and that also carried the CD45.2 allele, into lethally irradiated CD $45.1 \mathrm{Fab}^{-/}$recipients. The degree 
Table 1

Functional parameters of single-HSC-derived hepatocytes

\begin{tabular}{|c|c|c|c|c|}
\hline \multirow[b]{2}{*}{$\begin{array}{l}\text { Biochemical } \\
\text { parameter }\end{array}$} & \multicolumn{4}{|c|}{ Plasma levels \pm SD } \\
\hline & Units & $\begin{array}{l}\text { WT, } \\
n=5\end{array}$ & $\begin{array}{c}\text { FAH (single cell } \\
\text { transplanted), } n=3\end{array}$ & $\begin{array}{l}\text { FAH (untransplanted), } \\
\qquad n=3\end{array}$ \\
\hline ALT & $\mathrm{U} / \mathrm{l}$ & $45 \pm 10$ & $112 \pm 50$ & $407 \pm 30$ \\
\hline Direct bilirubin & $\mathrm{mg} / \mathrm{dl}$ & 0 & 0 & $5.88 \pm 2.5$ \\
\hline Tyrosine & $\mu \mathrm{M}$ & $54 \pm 15.1$ & $69.3 \pm 14$ & $617 \pm 18$ \\
\hline Methionine & $\mu \mathrm{M}$ & $41 \pm 4$ & $71.3 \pm 27$ & $170 \pm 6.7$ \\
\hline Alanine & $\mu \mathrm{M}$ & $257 \pm 41$ & $443 \pm 170$ & $1,858 \pm 186$ \\
\hline Glycine & $\mu \mathrm{M}$ & $163 \pm 14$ & $212 \pm 27$ & $466 \pm 49$ \\
\hline Glutamine & $\mu \mathrm{M}$ & $501 \pm 94$ & $521 \pm 123$ & $2,680 \pm 221$ \\
\hline Phenylalanine & $\mu \mathrm{M}$ & $58 \pm 6.5$ & $69 \pm 14$ & $89.7 \pm 10.5$ \\
\hline Ornithine & $\mu \mathrm{M}$ & $74 \pm 11$ & $108 \pm 34$ & $672 \pm 86$ \\
\hline
\end{tabular}

Data from $\mathrm{fah}^{-/-}$recipient mice represent analysis done at 4 months (one mouse) and 6 months (two mice) after transplantation. Untransplanted $\mathrm{Fah}^{-1}$ mice were kept off NTBC for 4 weeks before analysis was performed. ALT, Alamine aminotransferase.

Thus, although our experiments do not directly rule out that a few HSCs might be contributing to hepatocyte regeneration, they directly demonstrate that the great majority of this contribution is through a myeloid cell intermediate.

We designed an additional experiment to confirm the myeloid origin of the repopulating nodules. For this experiment we transplanted LysM BM into $\mathrm{Fab}^{-1-}$ recipients that also carried an allele for the $\mathrm{R} 26 \mathrm{R}$ reporter. In this context, only hematopoietic cells actively expressing high levels of Cre at the time of spontaneous fusion with hepatocytes would activate expression of $\beta$-gal in $\mathrm{Fah}^{-1-} / \mathrm{R} 26 \mathrm{R}$ host nuclei. Since expression of Cre in HSCs seems to be oscillatory and transient and at much lower levels than in myeloid cells (25), this experiment would more effectively rule out contribution by non-myelomonocytic progenitors. As expected, histochemical analysis of two livers of $\mathrm{Fab}^{-1-} / \mathrm{R} 26 \mathrm{R}$ recipients 5 months after transplantation revealed

of donor-derived hematopoietic chimerism in these hosts averaged $85 \% \pm 2.9 \%$ in their peripheral blood. In order to verify the myeloid specificity of LysM-Cre expression, donor CD45.2 blood cells were analyzed for $\beta$-gal expression. Whereas only $2-8 \%$ of circulating $B$ cells $\left(\mathrm{B} 220^{+}\right)$and $1-6 \%$ of T cells $\left(\mathrm{CD}^{+}\right)$expressed $\beta$-gal, more than $70 \%$ of granulocytic (Gr- $\left.1^{\text {high }}\right)$ and $80 \%$ of monocytic (Mac- $1^{\text {high }}$ ) cells were $\beta$-gal ${ }^{+}$(Figure $2 \mathrm{~A}$ ).

Six months after transplantation, all $\mathrm{Fab}^{-/-}$recipient mice were NTBC independent; thus, they were sacrificed and analyzed for donor-derived hepatic contribution by X-gal whole-mount staining of liver lobes. As a positive control, staining of livers of $\mathrm{Fab}^{-1-}$ mice transplanted with WBM from a ubiquitously expressed $\beta$-gal reporter (Rosa26 mice; ref. 24) revealed widespread engraftment with a typical nodular morphology (Figure 2B). In these Rosa26 WBM recipients, we estimated the average number of $\beta$-gal ${ }^{+}$nodules per liver to be $279 \pm 38$ (Table 2). Analysis of livers of LysM-Cre/R26R WBM recipients also demonstrated extensive hepatic repopulation with $\beta$-gal ${ }^{+}$myeloid-derived clusters (Figure $2 \mathrm{~B}$ ). The number of blue nodules was $247 \pm 45(n=4)$, similar to the control values. Further confirmation of the hepatic nature of the repopulation nodules was established by FAH immunohistochemistry (Figure 2C).

It was recently reported that the LysM promoter used in our experiments could also be active in a small number of pluripotent HSCs (25). Thus, it could be possible that HSCs were still directly responsible for the generation of hepatocytes. In our study, only 3-8\% of $\mathrm{Lin}^{-} \mathrm{Sca}-1^{+} \mathrm{CKit}^{+} \mathrm{SP}$ cells from LysM-Cre/R26R mice were positive for $\beta$-gal activity (data not shown). If HSCs were solely responsible for the entire BM hepatogenic activity, then we would only expect $3-8 \%$ of the number of marrowderived nodules to be lac $\mathrm{Z}^{+}$in our lineage-tracing experiment. Clearly this was not the case; the same number of lac $Z^{+}$nodules was obtained whether the transplanted BM was derived from LysM-Cre/R26R or constitutive Rosa26 mice. Furthermore, in the recipients of LysM-Cre/R26R BM, costaining of liver sections for $\mathrm{FAH}$ and lacZ revealed that the majority of nodules are positive for both markers (data not shown), thus demonstrating that all hepatocytes are derived from LysM-expressing progenitors.
Table 2

Contribution of different hematopoietic lineages to hepatocytes in the FAH model

\section{Discussion}

Our work here significantly extends the recent observations of fusion as a mechanism for BM-to-liver transdifferentiation (15, 16) by defining the specific cell lineage involved in these phenomena. Although our studies do not directly rule out a potential hepatic contribution by granulocytic cells, we hypothesize that within the myeloid lineage, differentiated macrophages are the cell entities that act as hepatic fusion partners. The fusogenic ability of macrophages has been described in the literature for more than a century. Langhans first described the presence of multinucleated giant cells in tuberculosis granulomas in 1869 (26). Langhans's giant cells, osteoclasts, and foreign-body giant cells were later shown to originate from the fusion of macrophage-lineage cells (26). Thus, it is very likely that the resident liver macrophages, the Kupffer cells, because of their abundance in the liver and proximity to hepatocytes, are the direct hepatocyte fusion partners.

\section{Recipient \\ Months after
transplantation}

Number of
lacZ+ nodules

$\begin{array}{lc}\text { Rosa26 }(n=5) & \text { Fah }^{-/-} \\ \text {Rag-2-/ } \gamma C^{-/-}(n=3) & \text { Fah }^{-/-} \\ \text {LysM-Cre/R26R }(n=4) & \text { Fah }^{-/-} \\ \text {LysM-Cre }(n=2) & \text { Fah }^{-/-/ R 26 R}\end{array}$

Donor cells were $1 \times 10^{6}$ freshly isolated BM cells. The number of lac $Z^{+}$nodules was determined by whole-mount $\mathrm{X}$-gal staining of liver lobes. The number of $\mathrm{FAH}^{+}$nodules was determined by analysis of $4-\mu \mathrm{m}$ paraffin-embedded sections stained with anti-FAH antibody. At least three liver sections from each mouse were analyzed. ND, not determined. 
Our results have important implications for the design of potential therapies based on the concept of stem cell plasticity. First, our data here and elsewhere (12) and the data of others (17) question the rationale behind clinical studies based on the idea that transdifferentiation of HSCs can lead to the de novo generation of heart or brain cells. Second, our observations that myeloid cells can act as fusogenic partners for hepatocytes and skeletal myofibers (12) raise the possibility that these cells or their derivatives could be used as vehicles for cellular therapy. Direct and localized administration of fusogenic cells could be an effective approach to deliver therapeutic DNA, bypassing the toxicity associated with traditional BM transplantation. Third, the fact that, after BM transplantation, Kupffer cells in the recipient livers are entirely donor-derived after 21 days (27) argues that recruitment of the fusogenic cell type is not the rate-limiting step in the generation of HSC-derived hepatocytes. Therefore, the extremely low incidence of initial BM-derived hepatocytes is due either to the low efficiency of fusion events in the liver or to the low probability of obtaining a productive nuclear reprogramming.

Finally, although our results argue against an unexpected developmental plasticity of HSCs, our work here and elsewhere (12) and the work of others (15-17) show that at least partial nuclear reprogramming of a differentiated adult cell can occur after cellular fusion. Activation of tissue-specific genes normally not expressed in hematopoietic cells has been reported in skeletal muscle (1, 3, $12)$, brain (28), and liver $(10,16)$. In the FAH model, hematopoietic myeloid nuclei are probably reprogrammed by transcription factors provided in trans by adjacent liver nuclei, which confer the function of FAH expression onto the donor nucleus, as well as a complete metabolic rescue. It will be interesting to see whether the donor nucleus undergoes an entire epigenetic reprogramming or whether only selected genes, necessary for selection and survival, are activated. Further investigation of the molecular mechanisms driving hepatocytespecific expression in hematopoietic cells could facilitate identification of the factors necessary for targeted reprogramming.

\section{Methods}

Single SP sorting. Single SP sorting and transplantation were done largely as described previously (12). Briefly, BM was flushed from the tibiae and femurs of 2-month-old Rosa26 transgenic mice backcrossed onto the C57BL/ 6 background that also expressed the CD45.2 allele. Hoechst 33342 staining (Sigma-Aldrich, St. Louis, Missouri, USA) and antibody incubations were performed as described previously (29). Sorting gates for single cells were set on the lowest part of the SP tail, shown to contain the most primitive HSCs (30), so that only $10 \%$ of the SP cells were selected. SP cells that were double positive for Sca- 1 and CD45 were then sorted on a triple-laser instrument (MoFlo; Cytomation Inc., Fort Collins, Colorado, USA). Single cells were sorted directly into individual wells of a flat-bottom 96-well plate containing $150 \mu \mathrm{l}$ of StemPro buffer (Invitrogen, Carlsbad, California, USA) by a single-cell deposition unit.

$H S C$ and WBM transplantation and analysis. Five- to six-week-old CD45.1 C57BL/6 mice were lethally

\section{Figure 2}

irradiated with 10 Gy of $\gamma$-irradiation in a split dose, with 3 hours between doses. The reconstituting cells were injected retro-orbitally within 24 hours of irradiation. In order to maximize the recovery of the single cells from wells, we first aspirated the contents of each well and then washed the same well with $150 \mu$ l of buffer containing the corresponding number of nontransgenic CD45.1 C57BL/6-carrier cells - either $1 \times 10^{5} \mathrm{WBM}$ cells depleted of cKit ${ }^{+} \mathrm{Sca}-1^{+}$doublepositive cells (in two experiments) or $600 \mathrm{Lin}^{-} \mathrm{Sca}-1^{+} \mathrm{CKit}{ }^{+} \mathrm{CD} 34^{\text {high }}$ cells (in one experiment). The volume in the well was then re-aspirated and injected. Carrier cells, isolated using the two parameters described above, are highly devoid of long-term HSC activity, and their in vivo lifespan ranges between 4 and 8 weeks (31). Mice were tested for hematopoietic engraftment at different time points beginning at 2 months after transplantation. For transplantation into secondary recipients, BM from two single-HSC primary recipients was harvested and stained with antibodies against CD45.2FITC (clone 104; Pharmingen, San Diego, California, USA) and CD45.1-phycoerythrin (CD45.1-PE) (clone A20). Approximately $18 \times 10^{6} \mathrm{CD} 45.2^{+}$cells from each mouse were then sorted, divided in two, and injected into lethally irradiated recipients. Levels of hematopoietic chimerism were tested by staining of peripheral blood leukocytes of recipients at various time points with CD45.2FITC and CD45.1-PE. For determination of hematopoietic lineage contribution, peripheral blood leukocytes were stained with antiCD45.2-FITC and antibodies against CD3(145-2C11), Thy-1 (30H12), B220 (RA3-6B2), Gr-1 (RB6-28C5), and Mac-1 (M1/70). All lineage antibodies were directly conjugated to FITC or PE-Cy 5 and purchased from eBioscience (San Diego, California, USA). Analysis of $\beta$-gal activity in hematopoietic cells of LysM-Cre/R26R mice was performed as previously reported (32).

Tissue injury models. Liver injury in mice transplanted with single Rosa 26 cells was induced by addition of DDC (Sigma-Aldrich, St.
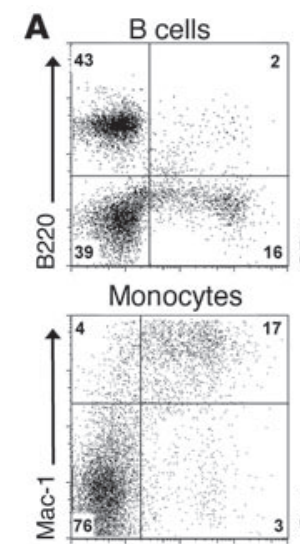

$\beta$-gal
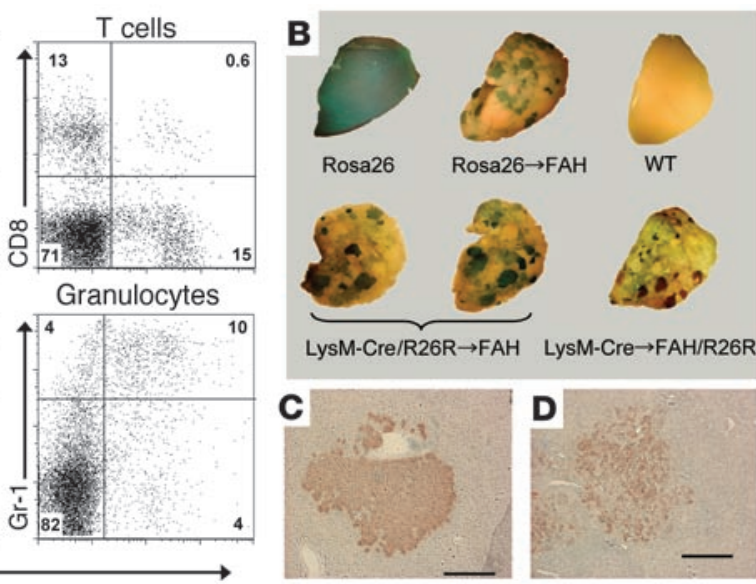

Myeloid-derived hepatocyte regeneration in $\mathrm{Fah}^{-/-}$hosts. (A) Cytofluorimetric analysis of peripheral blood from FAH mutant mice transplanted with LysM-Cre/R26R BM. The flow profiles shown were previously gated on CD45.2+ cells in order to restrict analysis to donor-derived cells. B220 was used as a B cell antibody, CD8 as a T cell antibody, and Gr-1 and Mac-1 as myeloid cell antibodies. (B) Histochemical detection of $\beta$-gal activity in $\mathrm{Fah}^{-/-}$recipient livers and controls. Rosa26 and wild-type livers were collected from untransplanted mice of the respective genotype. In the case of transplanted mice, the genotype preceding the arrow represents the donor WBM genotype. Host genotype is indicated after the arrow. (C and D) FAH immunohistochemistry on liver sections of recipients of LysM-Cre/R26R (C) and LysM-Cre (D) WBM, indicating donor-derived hepatocyte nodules. Scale bars: $200 \mu \mathrm{m}$. 
Louis, Missouri, USA) to the animals' feed at a concentration of $0.1 \%$ for 20 days at 6 months after transplantation.

Liver immunohistology. For whole-mount X-gal staining, liver lobes were fixed for 2 hours in $4 \%$ paraformaldehyde, and tissues were washed with PBS and moved to staining medium that contained $1 \mathrm{mg} / \mathrm{ml}$ of X-gal in buffer of $5 \mathrm{mmol} / \mathrm{l} \mathrm{K}$ ferricyanide, $5 \mathrm{mmol} /$ $1 \mathrm{~K}$ ferrocyanide, $2 \mathrm{mmol} / 1 \mathrm{MgCl}_{2}, 0.02 \%$ Nonidet P-40, and 40 $\mathrm{mmol} / \mathrm{l} \mathrm{HEPES}$. X-gal staining of frozen liver samples was done as described previously (33) on $10-\mu \mathrm{m}$ sections. Sections were then counterstained with light H\&E or nuclear fast red. For FAH immunohistochemistry, liver was fixed in 10\% neutral-buffered formalin, paraffin-embedded, and sectioned at $4 \mu \mathrm{m}$. FAH staining using a polyclonal rabbit antibody against rat FAH was performed as described (34). In order to quantify donor-derived hepatocytes in primary recipients, we analyzed 20 random sections from different liver lobes and reported the number of positive cells (large $\beta$-gal ${ }^{+}$ cells with abundant cytoplasm) per the total number of hepatocytes on the slides (this estimation was based on an average of 1,600 hepatocytes per square millimeter of mouse hepatic tissue).
Biochemical measurements. Amino acid levels were determined on a Beckman model 6300 amino acid analyzer.

\section{Acknowledgments}

M.A. Goodell is a scholar of the Leukemia and Lymphoma Society. This work was supported by NIH grants DK58192 and CA81179 to M.A. Goodell. F.D. Camargo was a fellow of the American Liver Foundation. We thank Markus Grompe (Oregon Health Sciences Center) for his gift of FAH mice, Lily Pao (Harvard Medical School) for LysM-Cre mice, Angela Major for immunohistochemistry, and Dorothy Burton for outstanding animal care.

Received for publication February 11, 2004, and accepted in revised form March 16, 2004.

Address correspondence to: Margaret A. Goodell, Center for Cell and Gene Therapy, Baylor College of Medicine, One Baylor Plaza, BCM505, Houston, Texas 77098, USA. Phone: (713) 798-1265; Fax: (713) 798-1230; E-mail: Goodell@bcm.tmc.edu.
1. Ferrari, G., et al. 1998. Muscle regeneration by bone marrow-derived myogenic progenitors. Science. 279:1528-1530.

2. Jackson, K.A., et al. 2001. Regeneration of ischemic cardiac muscle and vascular endothelium by adult stem cells. J. Clin. Invest. 107:1395-1402.

3. Gussoni, E., et al. 1999. Dystrophin expression in the $\mathrm{mdx}$ mouse restored by stem cell transplantation. Nature. 401:390-394.

4. Asahara, T., et al. 1999. Bone marrow origin of endothelial progenitor cells responsible for postnatal vasculogenesis in physiological and pathological neovascularization. Circ. Res. 85:221-228.

5. Mezey, E., Chandross, K.J., Harta, G., Maki, R.A., and McKercher, S.R. 2000. Turning blood into brain: cells bearing neuronal antigens generated in vivo from bone marrow. Science. 290:1779-1782

6. Krause, D.S., et al. 2001. Multi-organ, multi-lineage engraftment by a single bone marrow-derived stem cell. Cell. 105:369-377.

7. Okamoto, R., et al. 2002. Damaged epithelia regenerated by bone marrow-derived cells in the human gastrointestinal tract. Nat. Med. 8:1011-1017.

8. Korbling, M., et al. 2002. Hepatocytes and epithelial cells of donor origin in recipients of peripheralblood stem cells. N. Engl. J. Med. 346:738-746.

9. Theise, N.D., et al. 2000. Liver from bone marrow in humans. Hepatology. 32:11-16.

10. Lagasse, E., et al. 2000. Purified hematopoietic stem cells can differentiate into hepatocytes in vivo. Nat. Med. 6:1229-1234.

11. Petersen, B.E., et al. 1999. Bone marrow as a potential source of hepatic oval cells. Science. 284:1168-1170.

12. Camargo, F.D., Green, R., Capetenaki, Y., Jackson, K.A., and Goodell, M.A. 2003. Single hematopoietic stem cells generate skeletal muscle through myeloid intermediates. Nat. Med. 9:1520-1527.

13. Castro, R.F., et al. 2002. Failure of bone marrow cells to transdifferentiate into neural cells in vivo. Science. 297:1299.
14. Wagers, A.J., Sherwood, R.I., Christensen, J.L., and Weissman, I.L. 2002. Little evidence for developmental plasticity of adult hematopoietic stem cells. Science. 297:2256-2259.

15. Wang, X., et al. 2003. Cell fusion is the principal source of bone-marrow-derived hepatocytes. Nature. 422:897-901.

16. Vassilopoulos, G., Wang, P.R., and Russell, D.W. 2003. Transplanted bone marrow regenerates liver by cell fusion. Nature. 422:901-904.

17. Alvarez-Dolado, M., et al. 2003. Fusion of bonemarrow-derived cells with Purkinje neurons, cardiomyocytes and hepatocytes. Nature. 425:968-973.

18. Preisegger, K.H., et al. 1999. Atypical ductular proliferation and its inhibition by transforming growth factor beta1 in the 3,5-diethoxycarbonyl1,4-dihydrocollidine mouse model for chronic alcoholic liver disease. Lab. Invest. 79:103-109.

19. Grompe, M., et al. 1993. Loss of fumarylacetoacetate hydrolase is responsible for the neonatal hepatic dysfunction phenotype of lethal albino mice. Genes Dev. 7:2298-2307.

20. Wang, X., et al. 2002. Kinetics of liver repopulation after bone marrow transplantation. Am. J. Pathol. 161:565-574.

21. Colucci, F., et al. 1999. Dissecting NK cell development using a novel alymphoid mouse model: investigating the role of the $\mathrm{c}$-abl proto-oncogene in murine NK cell differentiation. J. Immunol. 162:2761-2765.

22. Clausen, B.E., Burkhardt, C., Reith, W., Renkawitz, R., and Forster, I. 1999. Conditional gene targeting in macrophages and granulocytes using LysMcre mice. Transgenic Res. 8:265-277.

23. Soriano, P. 1999. Generalized lacZ expression with the ROSA26 Cre reporter strain. Nat. Genet. 21:70-71.

24. Zambrowicz, B.P., et al. 1997. Disruption of overlapping transcripts in the ROSA beta geo 26 gene trap strain leads to widespread expression of beta- galactosidase in mouse embryos and hematopoietic cells. Proc. Natl. Acad. Sci. U. S. A. 94:3789-3794.

25. Ye, M., et al. 2003. Hematopoietic stem cells expressing the myeloid lysozyme gene retain longterm, multilineage repopulation potential. Immunity. 19:689-699.

26. Anderson, J.M. 2000. Multinucleated giant cells. Curr. Opin. Hematol. 7:40-47.

27. Naito, M., Hasegawa, G., and Takahashi, K. 1997. Development, differentiation, and maturation of Kupffer cells. Microsc. Res. Tech. 39:350-364.

28. Weimann, J.M., Johansson, C.B., Trejo, A., and Blau, H.M. 2003. Stable reprogrammed heterokaryons form spontaneously in Purkinje neurons after bone marrow transplant. Nat. Cell Biol. 5:959-966.

29. Goodell, M.A., Brose, K., Paradis, G., Conner, A.S., and Mulligan, R.C. 1996. Isolation and functional properties of murine hematopoietic stem cells that are replicating in vivo. J. Exp. Med. 183:1797-1806.

30. Goodell, M.A., et al. 1997. Dye efflux studies suggest that hematopoietic stem cells expressing low or undetectable levels of CD34 antigen exist in multiple species. Nat. Med. 3:1337-1345.

31. Osawa, M., Hanada, K., Hamada, H., and Nakauchi, H. 1996. Long-term lymphohematopoietic reconstitution by a single CD34-low/negative hematopoietic stem cell. Science. 273:242-245.

32. Nolan, G.P., Fiering, S., Nicolas, J.F., and Herzenberg, L.A. 1988. Fluorescence-activated cell analysis and sorting of viable mammalian cells based on beta-D-galactosidase activity after transduction of Escherichia coli lacZ. Proc. Natl. Acad. Sci. U. S. A. 85:2603-2607.

33. McKinney-Freeman, S.L., et al. 2002. Muscle-derived hematopoietic stem cells are hematopoietic in origin. Proc. Natl. Acad. Sci. U. S. A. 99:1341-1346.

34. Overturf, K., et al. 1996. Hepatocytes corrected by gene therapy are selected in vivo in a murine model of hereditary tyrosinaemia type I. Nat. Genet. 12:266-273. 


\section{Table 1}

Functional parameters of single-HSC-derived hepatocytes

\begin{tabular}{|c|c|c|c|c|}
\hline \multirow[b]{2}{*}{$\begin{array}{l}\text { Biochemical } \\
\text { parameter }\end{array}$} & \multicolumn{4}{|c|}{ Plasma levels \pm SD } \\
\hline & Units & $\begin{array}{l}\text { WT, } \\
n=5\end{array}$ & $\begin{array}{l}\text { FAH (single cell } \\
\text { transplanted), } n=3\end{array}$ & $\begin{array}{l}\text { FAH (untransplanted), } \\
\qquad n=3\end{array}$ \\
\hline ALT & $\mathrm{U} / \mathrm{I}$ & $45 \pm 10$ & $112 \pm 50$ & $407 \pm 30$ \\
\hline Direct bilirubin & $\mathrm{mg} / \mathrm{dl}$ & 0 & 0 & $5.88 \pm 2.5$ \\
\hline Tyrosine & $\mu \mathrm{M}$ & $54 \pm 15.1$ & $69.3 \pm 14$ & $617 \pm 18$ \\
\hline Methionine & $\mu \mathrm{M}$ & $41 \pm 4$ & $71.3 \pm 27$ & $170 \pm 6.7$ \\
\hline Alanine & $\mu \mathrm{M}$ & $257 \pm 41$ & $443 \pm 170$ & $1,858 \pm 186$ \\
\hline Glycine & $\mu \mathrm{M}$ & $163 \pm 14$ & $212 \pm 27$ & $466 \pm 49$ \\
\hline Glutamine & $\mu \mathrm{M}$ & $501 \pm 94$ & $521 \pm 123$ & $2,680 \pm 221$ \\
\hline Phenylalanine & $\mu \mathrm{M}$ & $58 \pm 6.5$ & $69 \pm 14$ & $89.7 \pm 10.5$ \\
\hline Ornithine & $\mu \mathrm{M}$ & $74 \pm 11$ & $108 \pm 34$ & $672 \pm 86$ \\
\hline
\end{tabular}

Data from $\mathrm{fah}^{-/-}$recipient mice represent analysis done at 4 months (one mouse) and 6 months (two mice) after transplantation. Untransplanted $\mathrm{Fah}^{-/}$mice were kept off NTBC for 4 weeks before analysis was performed. ALT, Alamine aminotransferase.

Table 2

Contribution of different hematopoietic lineages to hepatocytes in the FAH model

\begin{tabular}{|c|c|c|c|c|}
\hline Donor & Recipient & $\begin{array}{l}\text { Months after } \\
\text { transplantation }\end{array}$ & $\begin{array}{c}\text { Number of } \\
\text { lacZ+ nodules }\end{array}$ & $\begin{array}{c}\text { Number of } \\
\text { FAH+ nodules } \\
\text { per section }\end{array}$ \\
\hline Rosa26 $(n=5)$ & $\mathrm{Fah}^{-/-}$ & 6 & $279 \pm 38$ & $36 \pm 4$ \\
\hline Rag- $2^{-1} \gamma \mathrm{c}^{-/-}(n=3)$ & $\mathrm{Fah}^{-/-}$ & 6 & ND & $39 \pm 5$ \\
\hline LysM-Cre/R26R $(n=4)$ & ) $\mathrm{Fah}^{-/-}$ & 6 & $247 \pm 45$ & $38 \pm 3$ \\
\hline LysM-Cre $(n=2)$ & $\mathrm{Fah}^{-1-/ \mathrm{R} 26 \mathrm{R}}$ & 4.5 & $229 \pm 43$ & $32 \pm 5$ \\
\hline
\end{tabular}

Donor cells were $1 \times 10^{6}$ freshly isolated BM cells. The number of lac $Z^{+}$nodules was determined by whole-mount $\mathrm{X}$-gal staining of liver lobes. The number of $\mathrm{FAH}^{+}$nodules was determined by analysis of 4- $\mu \mathrm{m}$ paraffin-embedded sections stained with anti-FAH antibody. At least three liver sections from each mouse were analyzed. ND, not determined. 